\title{
From the Range to the Forest to the City
}

\section{A Case Study Collecting Experts' Perspectives on the Status of Landscape Connectivity in the Pikes Peak Region}

\author{
By Max J. Heitner
}

I $\mathrm{n}$ order to examine the subject of landscape connectivity, I chose to focus on a specific region where I could seek out local experts to discern their opinions on the matter. My primary objective was to consolide multiple qualified assessments in one place, where they could be analyzed for areas of agreement and disparity. The Pikes Peak Region was an ideal location for this case study because of the combination of its significant human development and the abundance and variety of wildlife. Landscape connectivity is a management consideration for how to best balance wildlife viability with continued human activity.

I chose to conduct a survey with open-ended questions in order to encourage a variety of responses and to limit any inherent biases within suggested answers. This survey method allowed for greater response rate among the limited potential respondents, while still providing informative qualitative narrative on the issue at hand. The major inhibiting factor for this study was the limited participant pool, because only those with the necessary credentials for being an expert on wildlife, park planning, and/or management were targeted for the survey.

How participants responded to survey questions varied. Some answered questions as representatives of their organizations, focusing on those priorities and limitations. Others answered independently of their position, offering their personal opinions on landscape connectivity in the Pikes Peak Region. Regardless, all responses shed some light onto how landscape connectivity is perceived in the region. However, because this is a regional case study, one must be careful not to make inferences or sweeping generalizations based on these results. Perspectives of landscape connectivity are not the same everywhere, and different locations carry with them specific considerations. This case study provides an additional point in the broader discussion of how landscape connectivity is perceived by wildlife, conservation, and planning experts.

\section{Landscape Connectivity: Why Is It Important?}

Achieving connectivity for natural areas and wildlife habitats is becoming an increasingly prioritized component of landscape planning. In order to do this, land managers and park planners who are trying to maintain connectivity for wildlife migration and long-term viability of wildlife populations utilize connectivity measures such as linkages and corridors. The goal of these connectivity measures is to lessen habitat fragmentation, which can cut off wildlife populations from one another. Once fragmented, wildlife populations have been shown to achieve lower genetic diversity, which can lead to genetic drift, inbreeding, lower evolutionary potential, and an increased risk of local extirpation. ${ }^{1}$ There are two widely-used methods of achieving connectivity in a fragmented landscape. The first is to protect larger-scale landscape linkages, which allow for the sharing of a multitude of ecological processes. ${ }^{2}$ The second method is conservation or construction of corridors, which are linear formations intended to accommodate the movement of specific species between larger habitat patches. ${ }^{2}$

The need for landscape connectivity and a framework of wildlife corridors and linkages was first noted with MacArthur and Wilson's theory of island biogeography. ${ }^{3}$ MacArthur and Wilson proposed that the success of bird populations on an island habitat is determined mainly by two factors: immigration and extinction. Their work showed that bird populations on islands closer to other islands, especially larger islands, had the highest population numbers. In essence, degree of isolation from other populations and habitat size were the greatest factors for wildlife success. MacArthur and Wilson's theory extended beyond actual islands with further research, confirming that population dynamics carried over to terrestrial ecosystems with similar predictability. ${ }^{4}$

The theory of island biogeography subsequently led to the SLOSS (single large or several small) debate in the 1970s and 1980s, which arose when discussing what habitats to prioritize for conservation. Although initially there was greater support for the prioritization of larger habitats, ${ }^{4}$ development of programs such as the "Biological Dynamics of Forest Fragments Project" in Brazil yielded a surge in inquiries concerning isolated habitats. In the past 20 years, much research has been published on "habitat is- 




Herd of pronghorn antelope (Antilocapra americana). Photograph by author.

lands," leading to a management shift towards connectivity management. Because the effect of habitat isolation proved detrimental on habitat populations, ${ }^{1,5}$ priority shifted to connecting habitats both large and small. The premise was that many different habitats joined together would lead to an increase in landscape function and suitability of habitat for wildlife.

Is the theorized increase in landscape function and habitat suitability the case in reality? Should landscape connectivity be a priority for planners and scientists? In order to respond to these questions, I designed a regional case study to focus on exploring connectivity with experts in the Pikes Peak Region.

\section{The Pikes Peak Region}

The targeted region for this case study was the Pikes Peak Region of Colorado. Located in central Colorado along the Front Range, the Pikes Peak Region contains extensive areas of rangelands, forests, and urban development. It is synonymous with the Colorado Springs Metropolitan Statistical Area as referenced by the United

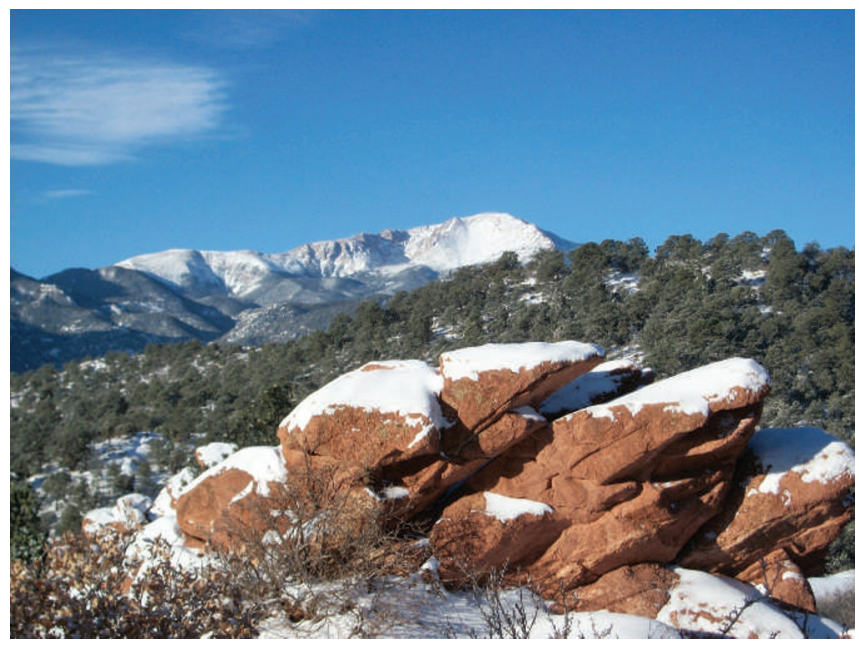

Pikes Peak from Garden of the Gods Park, Colorado. Photograph by author.

States Census Bureau. ${ }^{6}$ The Pikes Peak Region is the second-most highly populated metropolitan area in Colorado with 647,758 citizens in 2010. Colorado Springs accounts for most of these citizens, with over 416,000 within the city limits. ${ }^{6}$ Despite the size of the city, it manages to have an extensive network of parks and open spaces which are managed by the Colorado Springs Parks and Recreation Department and E1 Paso County Parks. This parks network has helped Colorado Springs to be recognized as a beacon for outdoor living. It was selected as the best big city in "Best Places to Live" in Money magazine in 2006, as well as being the number one selection in Outside magazine's 2009 list of America's best cities for outdoor living.

Outside of Colorado Springs lie the less-developed sections of El Paso and Teller counties. Here, in addition to city and county parks, federal- and state-owned lands comprise a large percentage of property holdings. The largest single holding of land in the region is Pike National Forest, managed by the United States Forest Service (USFS). One can also find the Florissant Fossil Beds National Monument, which is National

Table 1. Survey questions: opinion toward landscape connectivity measures and their effectiveness, 2010

\begin{tabular}{|c|c|}
\hline Number & Question \\
\hline 1 & How effective have connectivity measures (corridors and linkages) been in the Pikes Peak Region? \\
\hline 2 & What species are most impacted? \\
\hline 3 & How can wildlife corridors and landscape linkages be improved? \\
\hline 4 & Where do you think resources should be allocated to in the future (with regard to connectivity)? \\
\hline 5 & What is the biggest obstacle in the face of landscape connectivity for long-term conservation success? \\
\hline
\end{tabular}




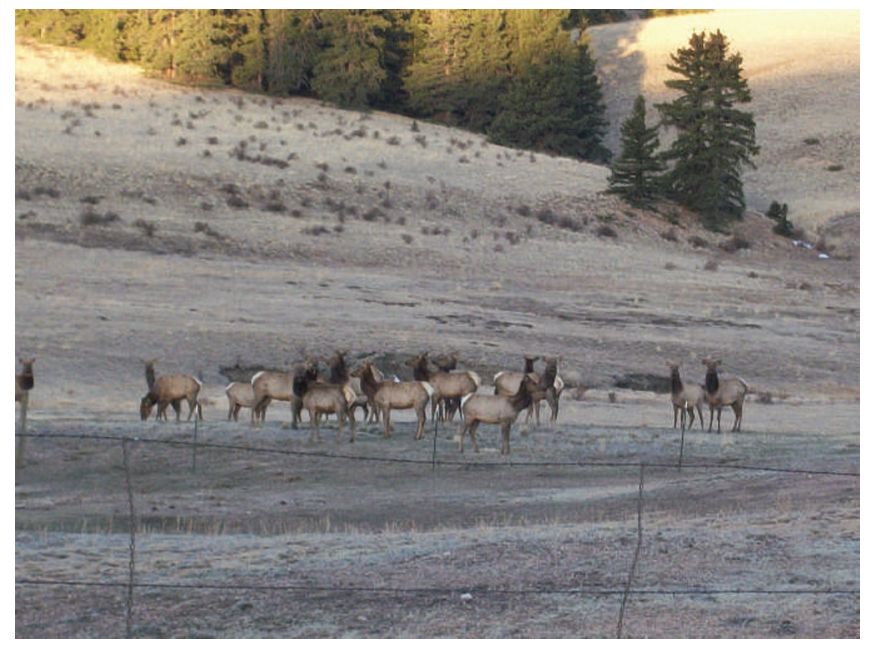

Herd of elk (Cervus canadensis). Photograph by author.

Park Service (NPS) land. There are state parks in the region as well, including Mueller State Park and Cheyenne Mountain State Park. In addition to these federal and state managed lands, there are thousands of acres of ranches and rangelands that are under both private and public designation. Although an increase in urban development is having an impact, the Pikes Peak Region still contains a thriving rural population in municipalities, such as Divide and Lake George, as well as in many unincorporated communities.

\section{Collecting Perspectives}

I chose to use a questionnaire to gather perspectives on local landscape connectivity. I asked experts in management, planning, and wildlife how effective the region is in promoting connectivity, and how effective current connectivity measures have been with regard to long-term wildlife viability (See

\section{Table 2. Participants in the study}

Colorado Division of Wildlife

\section{Colorado Springs Parks and Recreation}

Department of Geography and Environmental Studies, University of Colorado-Colorado Springs

\section{El Paso County Parks}

Palmer Land Trust

Pikes Peak Regional Council

United States Fish and Wildlife Service

United States Forest Service

\section{Table 3. Effectiveness of connectivity measures}

\begin{tabular}{|l|c|}
\hline Response & Mentions \\
\hline Positive & $25 \%$ \\
\hline Mixed & $25 \%$ \\
\hline Negative & $50 \%$ \\
\hline Total & $n=8$ \\
\hline
\end{tabular}

Table 1 for survey questions). Respondents (Table 2) stated current challenges and provided potential solutions. The questionnaire consisted of identifying questions followed by five open-ended questions regarding landscape connectivity in the region. Open-ended questions were chosen to encourage response variety and limit any inherent biases within suggested answers.

Response rate for the study was $73 \%$ (8 of 11), with a few targeted organizations and departments choosing not to participate due to lack of sufficient interest or knowledge on the subject. Statistical analysis of the survey results was limited because of the low respondent sample of eight. Statistics from this survey are meant to act as supplementary information to the qualitative responses (See Tables 3-7).

Some clear themes emerged when analyzing the questionnaire responses. Participants expressed the need for more land acquisition and more hands-on management of conservation lands. In addition, there seems to be a desire for more funding and for steps to be taken to increase social awareness of connectivity and its importance for wildlife.

When asked about the effectiveness of connectivity measures (Table 3), participants were most likely to see them as a work in progress, ineffective, or absent. Half of the participants responded negatively when asked to judge effectiveness of connectivity in the region. One participant said, "[The Pikes

Table 4. Species most impacted by landscape connectivity

\begin{tabular}{|l|c|}
\hline Response & Mentions \\
\hline Large mammals & $62.5 \%$ \\
\hline Birds & $37.5 \%$ \\
\hline Amphibians & $12.5 \%$ \\
\hline Total & $n=8$ \\
\hline
\end{tabular}


Peak Region] is losing its open lands at a faster rate than nearly any other comparably sized region in the nation." Another $25 \%$ of participants were mixed in their reaction, and only $25 \%$ of participants had a positive response. One with a brighter outlook said, "Rangeland provides connectivity in most cases [and the] USDA [US Department of Agriculture] and USFWS [US Fish and Wildlife Service] encourage correct rangeland management which will improve habitat for threatened species."

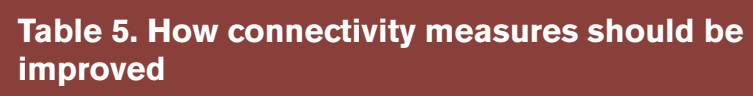

\begin{tabular}{|l|c|}
\hline Response & Mentions \\
\hline Increasing habitat & $62.5 \%$ \\
\hline Proper management & $37.5 \%$ \\
\hline Increasing public support & $25 \%$ \\
\hline Total & $n=8$ \\
\hline
\end{tabular}

Table 6. Where resources should be allocated in the future

\begin{tabular}{|l|c|}
\hline Response & Mentions \\
\hline $\begin{array}{l}\text { Acquiring more } \\
\text { conservation land }\end{array}$ & $62.5 \%$ \\
\hline Connecting existing lands & $37.5 \%$ \\
\hline Proper management & $25 \%$ \\
\hline Total & $n=8$ \\
\hline
\end{tabular}

Table 7. Obstacles for connectivity

\begin{tabular}{|l|c|}
\hline Response & Mentions \\
\hline Funding & $75 \%$ \\
\hline $\begin{array}{l}\text { Social and political } \\
\text { support }\end{array}$ & $62.5 \%$ \\
\hline Increased development & $25 \%$ \\
\hline Total & $n=8$ \\
\hline
\end{tabular}

Concerning species most impacted by connectivity (Table 4), large mammals were the most commonly cited (62.5\%). "Primarily large mammal species such as elk, mule deer, bobcat, mountain lion, and black bear" said one participant. Another added, "You certainly see species like mule deer, black bear, and elk being directly affected by vehicle collisions on roadways, but indirect effects are difficult to quantify." However, are these mammals really the most impacted by connectivity or are they the most valued by managers and planners? Because of their high visibility by citizens and tourists, large mammals are often prioritized in management plans. This must be considered when looking at the questionnaire results for Question 2 (Table 4). Birds were cited next as being highly impacted by connectivity (or the lack thereof). The types of birds varied; birds of prey, ground-dwelling birds, and songbirds all were mentioned by participants.

Question 3 of the survey asked how corridors and linkages can be improved (Table 5). The most frequent responses were: increasing suitable habitats $(62.5 \%)$, promoting proper management practices such as prescribed fires and appropriate fencing (37.5\%), and increasing public support (25\%). With regard to prioritizing land conservation, a participant called for "more conservation easements to protect critical areas." Another respondent, emphasizing management stated, "In one open space we use a wildlife friendly fence so antelopes [Pronghorn] can go under the fence, mule deer can go over the fence, and the barbed wire in the middle is intended to keep the cattle out." Another participant, with a more socially oriented response said, "It is a matter of finding the social and political will to enact measures that slow and reverse the trend of increased fragmentation. Proposals such as the wildlife overpass on Interstate 70 can help, too, if primarily as a means of educating the public."

Question 4 asked where resources should be allocated in the future (Table 6), and participants gave responses similar to those in Question 3. The most prevalent responses were: acquiring new conservation lands (62.5\%), connecting existing lands (37.5\%), and promoting proper wildlife management techniques (25\%). One participant stated, "Our main focus is to continue to make connections between existing facilities. We are still working on new trail sections and purchasing additional open space." Another participant added, "Resources should be placed in planning of landscape linkages, protecting land from development, and managing the habitat within the protected lands to benefit wildlife."

Despite the highly varied responses to the prior survey questions, participants were in clear agreement concerning the obstacles facing connectivity (Table 7). Funding (75\%) and social and political support (62.5\%) are seen as the major obstacles in the face of landscape connectivity for long-term conservation success. A participant stated potential obstacles as "land development regulations, public knowledge, [and] better incentives for landowners to place conservation easements on their property." Another 


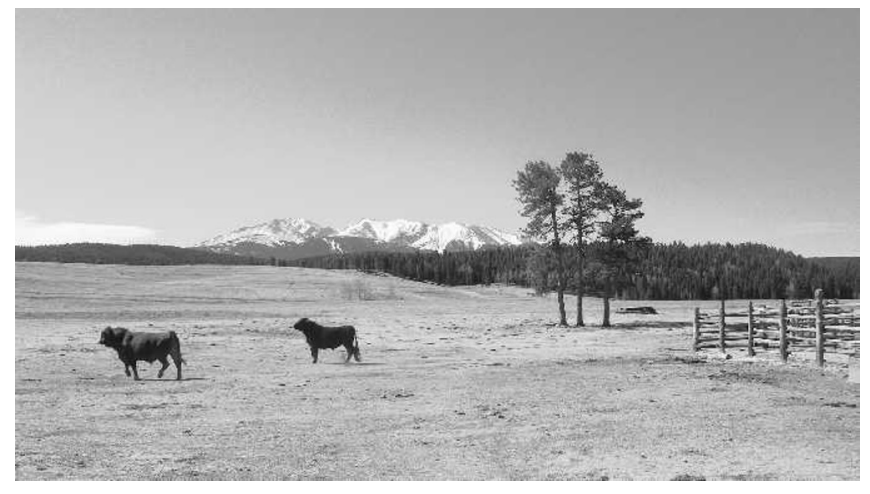

Rangeland along Highway 24 in Teller County, Colorado. Photograph by author.

issue mentioned by more than one participant was increasing road construction and residential development (25\%). "Residential developments and the expansion of motorized routes essentially represent a permanent loss of habitat and a barrier to migration corridors."

The responses to the questionnaire also pinpointed some areas of disparity among the participants. When asked about the effectiveness of connectivity measures in the region ( $\mathrm{Ta}-$ ble 3), some participants were able to discuss the subject thoroughly and in great detail, whereas others were unaware of any specific measures in the region. This indicated a potential lack of priority for connectivity in the management strategy of those specific organizations or departments. Going back to Question 2, most respondents cited large mammals as the primary populations to consider when managing for landscape connectivity. However, other participants focused on threatened and endangered species and were clearer in their selection of specific impacted species.

Questions 3 and 4 concerned the subject of how connectivity can be improved and where resources should be allocated. There was a clear discrepancy among participants on whether they prioritized land acquisition or land management. This is a common debate for conservation funding initiatives, and this case study adds evidence that this will continue to be a point of contention among various managing departments and organizations. In addition, there were also areas that were mentioned only by one or two participants. For example, two participants (25\%) brought up the importance of logging/forest roads and the potential impact of the removal of these roads. In addition, there was only one mention (12.5\%) of increasing efforts to research connectivity. Further research on the effectiveness of various linkages and corridors and their impact on specific species seems to be of lower priority to experts in the region than continued land acquisition and management.

\section{Regional Landscape Connectivity: Moving Forward}

The perspectives collected in this case study explored management tools used to balance humans and wildlife living in close proximity to one another. Perspectives from managers, planners, and scientists can impact the future management of connectivity in the Pikes Peak Region. By outlining the areas where these experts agree and disagree on landscape connectivity, we are able to narrow the focus for future connectivity plans.

Judging by the opinions of the participants, priority for any connectivity plan should be given to land acquisition and proper management of those lands. The targeted lands for acquisition would preferably connect to existing conservation lands, and should be actively managed with prescribed fires and proper fencing to promote movement along the landscape by an array of wildlife. Extensive efforts should simultaneously be made in garnering political and social support for the utilization of monetary resources for connectivity conservation and management. These recommendations, collected from regional planning and management experts, could be the beginning of a long-term regional connectivity plan for the Pikes Peak Region.

Regional planning is already used in other environmental topic areas, such as watershed management. Regional-scale planning for connectivity could be included within a regional land-use plan, taking into account connection as a necessity for proper wildlife management. Incorporating an array of stakeholders is crucial, including governmental departments, non-profit organizations, and developers, to create a feasible plan with the potential to attain long-term goals. Any regional connectivity plan must be realistic in order to increase chances of implementation, and a policy framework should prioritize conservation goals along with local economic growth and prosperity.

Few conservation goals can be achieved without the support of a multitude of organizations and individuals. Respondents in this study valued the impact that social awareness can have to establish funding and support to put a conservation issue at the forefront of policy changes. Without the support of citizens, it will be an uphill battle to achieve a long-term regional connectivity plan. As mentioned by a participant in this study, the proposed wildlife crossing on Interstate 70 outside Vail, Colorado (120 miles northwest of the Pikes Peak region) has the opportunity to not only lessen wildlife-vehicle collisions and improve wildlife movement, but also greatly increase public awareness of connectivity and its importance for both humans and wildlife. In Banff, Alberta, Canada, significant investment has been put into the construction of overpasses and underpasses for wildlife to cross the four-lane Trans-Canada Highway. Studies have shown significant reduction in wildlife-vehicle collisions after the construction of the wildlife passes with extensive fencing funneling the animals to the crossings. ${ }^{7}$ While serving to lessen the rate of wildlife-vehicle collisions and educate the public, high-profile wildlife crossings also could be significant for future connectivity management.

In addition to garnering social and political support, it will be important to create cohesion amongst the various man- 
aging stakeholders of land and wildlife in the region. The creation of a consortium of wildlife biologists, park planners, and managers from various departments would lead to the sharing of ideas and, potentially, a formal connectivity plan for the region. Regional connectivity planning can provide guidance, and help to promote long-term decision-making, creating a more viable future for the conservation of the Pikes Peak Region's wildlife and its habitats.

\section{References}

1. Reed, D. H., and R. Frankham. 2003. Correlation between fitness and genetic diversity. Conservation Biology 17:230-237.

2. Morrison, S. A., And W. M Boyce. 2008. Conserving connectivity: some lessons from mountain lions in southern California. Conservation Biology 23:275-285.

3. MacArthur, R. H., and E. O Wilson. 1967. The theory of island biogeography. Princeton, NJ: Princeton University Press. 203 p.
4. Diamond, J. M. 1975. The island dilemma: lessons of modern biogeography studies for the design of natural reserves. Biological Conservation 7:129-146.

5. Dixo, M., J. P. Metzger, J. S. Morgante, and K. R. ZamuDIO. 2008. Habitat fragmentation reduces genetic diversity and connectivity among toad populations in the Brazilian Atlantic Coastal Forest. Biological Conservation 142:1560-1569.

6. US Census Bureau. 2010. American FactFinder Quickfacts. Colorado Springs Metropolitan Statistical Area, CO, USA. Available at: http://quickfacts.census.gov. Accessed 11 December 2011.

7. Clevvenger, A. P., And N. Waltho. 2000. Factors influencing the effectiveness of wildlife underpasses in Banff National Park, Alberta, Canada. Conservation Biology 14:47-56.

Author is Land Management Specialist, Dept of Natural Resources and Environmental Sciences, University of Illinois at UrbanaChampaign,Urbana, IL 61801, USA, max.heitner@gmail.com. 